prove Parkinson's disease, is added testimony to the efficacy of the drug. It appears that L-dopa is now the drug of choice in the management of patients with this disease. This is not to deny that treatment at an optimum level requires frequent assessment and careful adjustment of dosage to the individual's particular needs, and that side-effects are frequent and of ten dose-limiting.

We express thanks to Dr. L. Lasagna and Dr. T. Preziozi for continued interest and support and to R. M. Hersey for invaluable technical help. Dr. A. Pletscher (Hoffman-La Roche, Basle, Switzerland) kindly supplied the ${ }^{1+} \mathrm{C}-\mathrm{L}-\mathrm{dopa}$, and Dr. W. B. Abrams (Hoffman-La Roche, Nutley, New Jersey) supplied the pure L-dopa used in these studies.

Requests for reprints should be addressed to Dr. M. J. T. Peaston.
REFERENCES

Alba, A., Trainor, F. S., Ritter, W., and Dacso, M. M. (1968). fournal of Chronic Diseases, 21, 507

Bray, G. A. (1960). Analytical Biochemistry, 1, 279.

Calne, D. B., Stern, G. M., Laurence, D. R., Sharkey, J., and Armitage, P. (1969). Lancet, 1, 744

Cotzias, G. C., Papavasiliou, P. S., and Gellene, R. (1968). Neurology (Minneapolis), 18, 276

Cotzias, G. C., Papavasiliou, P. S., and Gellene, R. (1969). New England fournal of Medicine, 280, 337

Fredrickson, D. S., and Ono, K. (1958). Fournal of Laboratory and Clinical Medicine, 51, 147.

Godwin-Austen, R. B., Tomlinson, E. B., Frears, C. C., and Kok, H. W. L. (1969). Lancet, 2, 165 .

Johns, R. J., and Draper, I. T. (1964). Bulletin of the Fohns Hopkins Hospital, 115, 447.

Kelly, R. G., Peets, E. A., Gordon, S., and Buyske, D. A. (1961). Analytical Biochemistry, 2, 267

Yahr, M. D., Duvoisin, R. C., Hoehn, M. M., Schear, M. J., and Barrett, R. E. (1968). Transactions of the American Neurological As sociation, $93,56$.

\title{
Studies of Australia-SH Antigen in Sporadic Viral Hepatitis in London
}

\author{
YVONNE E. COSSART, ${ }^{*}$ M.B., M.R.C.PATH. ; J. VAHRMAN, $†$ M.B., M.R.C.P.ED.
}

British Medical fournal, 1970, 1, 403-405

\begin{abstract}
ummary: Sera from 87 patients with acute sporadic viral hepatitis were tested for the presence of the Australia-SH antigen. Forty-three were positive by the complement-fixation test, but only 24 of these reacted in the gel-diffusion test. The antigen was equally distributed in infectious and serum hepatitis. The relationship of naturally occurring antigen-positive hepatitis to the Willowbrook MS-2 type is discussed.
\end{abstract}

\section{Introduction}

The relationship of the Australia-SH (Au-SH) antigen to the different types of viral hepatitis is still uncertain. The antigen may sometimes be detected in the serum early in the disease, but its frequency in infectious and serum hepatitis appears to vary widely (Table I). This variation is not likely to be due to difference in laboratory technique as good agreement was obtained when five "anti-Au-SH" sera were compared by the gel-diffusion method (Cossart, Taylor, Vahrman, and Zuckerman, 1969). It has recently been shown that much lower concentrations of antigen can be detected by the complementfixation test (Shulman and Barker, 1969). We have therefore used both the gel-diffusion and complement-fixation methods to examine sera from 87 cases of naturally occurring viral hepatitis admitted to the Western Hospital, London, during the past four years and have attempted to correlate the presence of the antigen with the clinical types of the disease.

\section{Patients Studied}

Blood and faecal specimens were obtained from 87 patients soon after admission to hospital. None had received blood transfusions and none were associated with a renal dialysis unit or admitted to using narcotic drugs. Patients with clinical or laboratory evidence of infectious mononucleosis or cytomegalovirus infection were excluded from the study. Though no deliberate selection was made material was not obtained \footnotetext{
* Consultant Virologist, Virus Reference Laboratory, Colindale, London

† Consultant in Infectious Diseases, Western Hospital, London S.W.6.
}

from every patient with hepatitis. There was a period of 11 months after May 1966 during which collection of specimens was suspended.

Two types of viral hepatitis were distinguished: (1) infectious hepatitis (I.H.) with a short incubation period (15 to 40 days) after an injection, contact with another case, or a visit to an endemic area; and (2) serum hepatitis (S.H.) with a long incubation period (60 to 180 days) after an injection or with a history of arthralgia of the small joints.

Patients whose history contained no positive features of either category were placed in the I.H. group. In some patients there were points in favour of both diagnoses, and these have been considered as a third group.

\section{Laboratory Methods}

The same antiserum (L.B.) was used for both gel-diffusion and complement-fixation tests. It was obtained from a haemophiliac who had received many transfusions of blood, fresh frozen plasma, and cryoprecipitate. Its specificity has been compared with that of the anti-Au and anti-S.H. reference sera kindly supplied by Dr. B. S. Blumberg and Dr. A. M. Prince respectively. The three sera had almost identical properties in the gel-diffusion test (Cossart et al., 1969).

The gel-diffusion tests were performed in $1 \%$ agarose (Prince, 1968).

The complement-fixation tests were performed by a micromethod with a 4 ( $\times 0.02 \mathrm{ml}$.) volume technique, overnight fixation at $4{ }^{\circ} \mathrm{C}$., and $2 \frac{1}{2}$ units of complement; $50 \%$ endpoints were recorded.

All sera were inactivated at $56^{\circ} \mathrm{C}$. for one hour before use and serial twofold dilutions of sera from hepatitis patients were tested against one dilution of indicator serum L.B. which contained 4 units of antibody.

For the indirect test the initial mixtures which contained serial twofold dilutions of the patient's convalescent serum, and 4 units of antigen, were held for three hours at room temperature before serum L.B. and complement were added. Fixation was then allowed to proceed at $4^{\circ} \mathrm{C}$. overnight.

Ten per cent faecal extracts were made in Medium 199 and after centrifugation at 3,000 r.p.m. for 15 minutes the supernatant fluids were tested in the presence of antigen by gel 
TABle I.-Australia-SH Antigen in Patients' Sera

\begin{tabular}{|c|c|c|c|c|c|c|c|}
\hline \multirow{2}{*}{ Authors } & \multicolumn{2}{|c|}{ Infectious Hepatitis } & \multicolumn{2}{|c|}{ Serum Hepatitis } & \multicolumn{2}{|c|}{ Viral Hepatitis } & \multirow{2}{*}{ Comment } \\
\hline & No. & $\%$ Positive & No. & $\%$ Positive & No. & $\%$ Positive & \\
\hline Gocke and Kavey (1969) & $7 / 15$ & 46 & $36 / 48$ & 75 & $6 / 14$ & 43 & $\begin{array}{l}\text { If only patients whose sera } \\
\text { collected before day } 14 \text { are } \\
\text { included } 82 \% \text { S.H., } \\
83 \% \text { I.H., and } 67 \% \text { V.H. } \\
\text { positive }\end{array}$ \\
\hline London, Sutnick, and Blumberg (1969) & $10 / 84$ & 13 & $14 / 41$ & 34 & N.D.C. & N.D.C. & \\
\hline Okochi and Murakami (1968) .. & N.D.C. & N.D.C. & $13 / 111$ & 10 & $10 / 66$ & 17 & S.H. entirely post-transfusion \\
\hline Prince (1968) & N.D.C. & N.D.C. & N.D.C. & N.D.C. & 5 & 20 & S.H. entirely post-transfusion \\
\hline Prince (1969) & ? & 40 & $?$ & 50 & & & S.H. entirely post-transfusion \\
\hline Shulman and Barker (1969) & 112 & $\begin{array}{c}68 \% \text { gel. } 98 \% \\
\text { C.F.T. }\end{array}$ & 24 & $\begin{array}{l}8 \% \text { gel. } 54 \% \\
\text { C.F.T. }\end{array}$ & N.D.C. & N.D.C. & I.H. all from Ghana \\
\hline Wright, McCollum, and Klatskin (1969) & $3 / 12$ & 25 & $21 / 43$ & 49 & $22 / 33$ & 67 & $\begin{array}{l}\text { I.H. includes only cases with } \\
\text { history of contact, eating } \\
\text { clams, or travel to endemic } \\
\text { area }\end{array}$ \\
\hline
\end{tabular}

N.D.C. $=$ Not differentiated clinically. C.F.T. $=$ Complement-fixation test.

diffusion. They were then concentrated 100 -fold with carbowax and retested.

For electron microscopy $0.5 \mathrm{ml}$. of test and $0.1 \mathrm{ml}$. of detector serum were mixed, and after standing at $37^{\circ} \mathrm{C}$. for one hour, then at $4^{\circ} \mathrm{C}$. overnight, they were diluted to $12 \mathrm{ml}$. with Medium 199 and ultracentrifuged at 41,000 r.p.m. for 75 minutes. The pellets were resuspended in $0.1 \mathrm{ml}$. of distilled water, negatively stained with $2 \%$ sodium silicotungstate, and examined in an AEI EM6B electron microscope at magnifications of $\times 60,000$ and $\times 100,000$.

\section{Results}

The occurrence of Au-SH antigen in the first specimen of serum obtained from the 87 patients is shown in Table II. Of the sera $51 \%$ were completely negative, $27 \%$ were positive by both gel-diffusion, and complement-fixation test, and $22 \%$ TABLE II.-Number of Cases where Au-SH Antigen was Detected in the
First Serum

\begin{tabular}{|c|c|c|c|c|c|c|c|c|}
\hline & & & 1965 & 1966 & 1967 & 1968 & 1969 & Total \\
\hline $\begin{array}{l}\text { Positive by gel and C.F.T. } \\
\text { Positive by C.F.T. only } \\
\text { Negative } \quad . \quad \ldots\end{array}$ & $\begin{array}{l}\cdots \\
\cdots \\
\cdots\end{array}$ & $\begin{array}{l}\cdots \\
\cdots\end{array}$ & $\begin{array}{r}6 \\
6 \\
15\end{array}$ & $\begin{array}{l}2 \\
3 \\
9\end{array}$ & $\begin{array}{l}2 \\
1 \\
2\end{array}$ & $\begin{array}{l}4 \\
4 \\
3\end{array}$ & $\begin{array}{r}10 \\
5 \\
15\end{array}$ & $\begin{array}{l}24 \\
19 \\
44\end{array}$ \\
\hline Total positive & & & $\mathbf{4 4} \%$ & $35 \%$ & $60 \%$ & $73 \%$ & $50 \%$ & $49 \%$ \\
\hline
\end{tabular}

positive by complement-fixation test only. In general the sera with high titres in the complement-fixation test also reacted in the gel-diffusion test, $90 \%$ of those producing lines in the geldiffusion test having complement-fixation titres of $\frac{1}{64}$ or higher, compared with $30 \%$ of those which did not. There were, however, four sera which had high titres in the complement-fixation test but failed to react in the gel-diffusion test.

Our detector serum was of human origin and so probably contained antibodies to common microbial agents quite unrelated to hepatitis. Because we were not sure of the significance of these positive complement-fixation tests we looked for Au$\mathrm{SH}$ antigen particles in three sera-one negative by gel-diffusion despite a high complement-fixation titre, one positive by both gel-diffusion and complement-fixation test, and one normal control. No virus-like particles were seen in the normal control, but both other sera contained clumps of particles $200 \AA$. in diameter similar to those described by Bayer, Blumberg, and Werner (1968) and Almeida, Zuckerman, Taylor, and Waterson (1969).

It has been shown (Prince, 1968; Gocke and Kavey, 1969) that antigen is present in the early stages of the illness and then disappears quickly. Late presentation of cases might therefore increase the proportion of negative results. This is unlikely in the present series, however, since specimens of serum which were negative were obtained on average three days earlier than those which were positive (Table III).

TABLE III.-Time After Onset When Specimens Obtained

\begin{tabular}{|c|c|c|c|}
\hline & & Average (Days) & Range (Days) \\
\hline \multirow{2}{*}{ Au-SH antigen present } & \multirow{2}{*}{$\begin{array}{l}\text { Total } \\
\text { Positive by } \\
\text { C.F.T. only }\end{array}$} & 13.8 & $4-35$ \\
\hline & & $13 \cdot 0$ & 6-32 \\
\hline Au-SH antigen absent & .. & 9.5 & $4-17$ \\
\hline
\end{tabular}

A second specimen of serum was tested from 13 patients whose previous serum had contained antigen. Eleven were found to be negative by the gel-diffusion test, but nine still contained antigen detectable by complement fixation (Table IV). There was no correlation between time after onset, return

Table IV.-Detection of Au-SH Antigen in Paired Sera

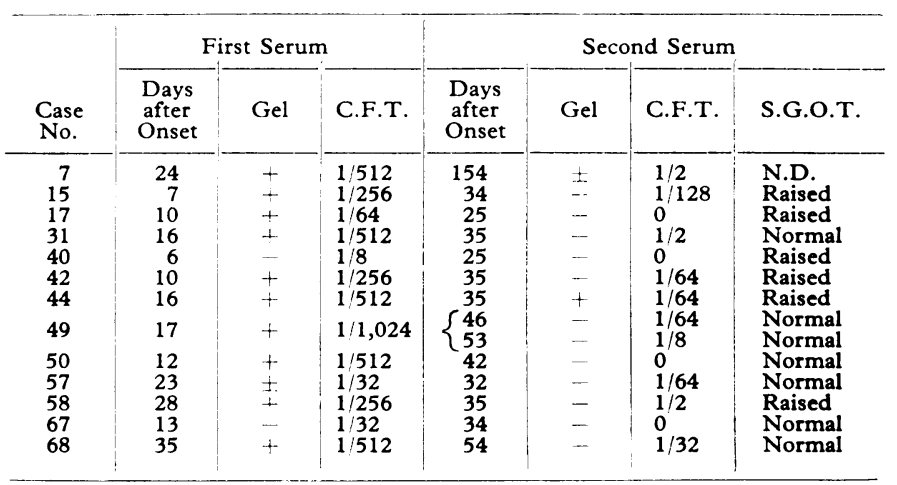

N.D. $=$ Not done.

of the serum transaminase to normal, and loss of antigen from the serum. Convalescent stage sera from Cases 49 and 67 were examined by indirect complement-fixation test with the antigen previously present in the homologous sera, but no antibody was found.

Faecal specimens from Cases 49, 58, 67 and 69 were collected at the same time as the first sera which contained antigen: $10 \%$ faecal extracts were prepared, but the gel-diffusion technique failed to detect antigen even after these extracts had been concentrated 100 -fold.

When we divided our patients into the three clinical categories listed above the percentage positive in the I.H., S.H., and undetermined groups was almost the same (Table V). About $30 \%$ of the patients were positive by both the geldiffusion and complement-fixation tests, $20 \%$ positive by complement-fixation test alone, and $50 \%$ negative. Fifteen of the 
Table V.-Clinical Category Related to the Presence of Antigen

\begin{tabular}{|c|c|c|c|c|c|}
\hline & & I.H. & S.H. & I.H. or S.H. & Total \\
\hline $\begin{array}{l}\text { Positive by gel and C.F.T. } \\
\text { Positive by C.F.T. only } \\
\text { Negative } \quad . \quad \ldots \\
\end{array}$ & $\begin{array}{l}\cdots \\
\cdots \\
\cdots\end{array}$ & $\begin{array}{l}16 \\
15 \\
35 \\
\end{array}$ & $\begin{array}{l}4 \\
3 \\
6 \\
\end{array}$ & $\begin{array}{l}4 \\
1 \\
3 \\
\end{array}$ & $\begin{array}{l}24 \\
19 \\
44 \\
\end{array}$ \\
\hline Total positive & . & $47 \%$ & $54 \%$ & $63 \%$ & $49 \%$ \\
\hline
\end{tabular}

43 patients whose serum contained antigen gave no history of injection during the nine months preceding the onset of illness.

When the cases are divided into $\mathrm{Au}-\mathrm{SH}$ antigen-positive and antigen-negative groups two differences emerge. Firstly, the antigen-positive group contains many more males than females, the ratio being $4.5: 1$, while in the antigen-negative group the ratio is $1: 1$. Secondly, while the clinical features of the two groups were very similar there was a tendency for the serum aspartate aminotransferase (S.G.O.T.) to remain raised longer and to fluctuate more in the antigen-positive patients. The S.G.O.T. in $90 \%$ of antigen-negative patients fell below 100. units by the fifth week of illness, but this was not attained by $90 \%$ of the antigen-positive group until the eighth week.

\section{Discussion}

The Au-SH antigen was present in the serum of about half our patients with sporadic hepatitis at the time they were admitted to hospital. The antigen was detected twice as commonly by the complement-fixation test as by the gel-diff $\mathrm{L}$ sion method in sera from patients in the early stages of the disease. The greater sensitivity of the complement-fixation test detected antigen in a number of sera in which the gel-diffusion test did not, but this could not be correlated with continued activity of the disease.

We did not encounter any sera which reacted only in the gel-diffusion test. Purcell et al. (1969), however, found a small number positive by the gel-diffusion test alone. Confidence in the specificity of the complement-fixation test was increased by finding Au-SH particles by electron microscopy in serum with a high complement-fixation titre which failed to react in the gel-diffusion test. The main disadvantage of the complement-fixation test is that a prozone effect is not uncommon, and all test sera must therefore be titrated with considerable quantities of detector serum.

Prince $(1968,1969)$ maintained that the Au-SH antigen is associated mainly with serum hepatitis, but others believe that the antigen is also to be found in most cases of infectious hepatitis (Gocke and Kavey, 1969; Shulman and Barker, 1969). The series so far published showed appreciable variation in results (Table I). These differences partly result from the use of different criteria for the subdivision of cases. Some exclude patients without a history of contact from the I.H. group, and in some the S.H. group consists entirely of post-transfusion hepatitis.

We found the antigen in almost equal proportions in I.H. and S.H. groups. In considering this result it should be remembered that none of these patients were infected during an epidemic of hepatitis or suffered from "homologous serum jaundice." We often found difficulty in assigning patients to the I.H. or the S.H. group, because neither the length of the incubation period nor the source of infection could be reliably established. A history of contact with a jaundiced person was seldom obtained. This is to be expected, since anicteric and subclinical cases of hepatitis are not uncommon. The length of the incubation period is often in doubt because the onset of illness is often insidious. Even when the infection seems to have been transmitted by an injection its exact date must be known since both I.H. and S.H. have been transmitted parenterally (MacCallum and Bradley, 1944). Hepatitis is so commonly encountered that a history of contact, injection, or travel to an endemic area may all be incidental to the patient's illness. For these reasons the division of hepatitis into I.H. and S.H. is not satisfactory in practice.

Another approach to the problem was made by the Willowbrook group, who reported (Krugman, Giles, and Hammond, 1967) the experimental separation of two immunologically distinct forms of hepatitis in children from their institution. These were found to differ in the length of their incubation period and the duration of their clinical course. The strain MS-1 with the short incubation period (35 to 47 days) and short duration resembles I.H.; the long incubation (41 to 108 days) strain MS-2 had a longer course like that of S.H., and though both types have been transmitted by mouth as well as by injection the MS-2 type was much less infectious to contacts. Prince (1968) and Giles, McCollum, Berndtson and Krugman (1969) have shown that the Au-SH antigen was regularly associated with the MS-2 type of infection but the MS-1 type is always antigen-negative.

When our antigen-positive patients were considered as a group their serum transaminase levels remained raised longer and fluctuated more than those of the antigen-negative group. In this feature the group behaved like the MS-2 and MS-1 types respectively.

Parenteral inoculation was not the obvious route of infection in at least one-third of the patients whose serum contained antigen. This suggested that the oral route was to some extent involved in the natural spread of this type of hepatitis, another similarity with the MS-2 type. It should, however, be recalled that S.H. has been observed to spread to contacts (Mirick and Shank, 1959).

Sex distribution, too, was different in the antigen-positive and antigen-negative groups. Males outnumbered females by 4.5:1 in the antigen-positive group, while the ratio in the antigen-negative cases was $1: 1$. This difference does not seem to be due to social factors favouring early admission of males to hospital, as the overall sex ratio in our series was two males to one female. A similar male predominance was reported for antigen carriers among Japanese blood donors (Okochi and Murakami, 1968). Our findings need confirmation because our patients came from an area with a large floating population and the series was not a completely consecutive one, but they suggest that antigen-positive and antigen-negative hepatitis may be two distinct clinical entities and that subdivision into these types may prove more fruitful for the study of hepatitis clinically and epidemiologically than the division of viral hepatitis into infectious and serum types.

Our thanks are due to Dr. M. G. Rinsler for allowing us to use the serum transaminase results, to Dr. Anne M. Field for examining our specimens by electron microscopy, and to Dr. P. A. Vakil for his help in the clinical part of the investigation.

\section{REFERENCES} Almeida, J. D., Zuckerman, A. J., Taylor, P. E., and Waterson, A. P.
(1969). Microbios, 1, 117.

Bayer, M. E., Blumberg, B. S., and Werner, B. (1968). Nature, 218, 1057.

Cossart, Y., Taylor, P. E., Vahrman, J., and Zuckerman, A. J. (1969). British Medical fournal, 3, 755.

Giles, J. P., McCollum, R. W., Berndtson, L. W., and Krugman, S. (1969). New England fournal of Medicine, 281, 119.

Gocke, D. J., and Kavey, N. B. (1969). Lancet, 1, 1055

Krugman, S., Giles, J. P., and Hammond, J. (1967). Fournal of the American Medical Association, 200, 365 .

London, W. T., Sutnick, A. I., and Blumberg, B. S. (1969). Annals of Internal Medicine, 70, 55.

MacCallum, F. O., and Bradley, W. H. (1944). Lancet, 2, 228.

Mirick, G. S., and Shank, R. E. (1959). Transactions of the American Clinical and Climatological Association, 71, 176.

Okochi, K., and Murakami, S. (1968). Vox Sanguinis, 15, 374.

Prince, A. M. (1968). Proceedings of the National Academy of Sciences of the United States of America, $60,814$.

Prince, A. M. (1969). New England fournal of Medicine, 281, 163.

Purcell, R. H., et al. (1969). Fournal of Infectious Diseases, 120, 383.

Shulman, N. R., and Barker, L. F. (1969). Science, 165, 304.

Wright, R., McCollum, R. W., and Klatskin, G. (1969). Lancet, 2, 117. 